\title{
En el cuadragésimo aniversario de Laborem Exercens: la espiritualidad del trabajo
}

\section{Horacio Rodríguez-Penelas* \\ Pontificia Universidad Católica Argentina hrp@uca.edu.ar \\ Revista Cultura Económica \\ Año XXXIX $\bullet \mathrm{N}^{\circ} 102$ \\ Diciembre 2021: 119-141 \\ https://doi.org/10.46553/cecon.39.102.2021.p119-141}

Resumen: Este año (2021) el Papa Francisco beatificó al Cardenal Stephan Wyszynski el 12 de septiembre, dos días antes del cuadragésimo aniversario de Laborem Exercens. Este ensayo presenta algunos aspectos del libro El espíritu del trabajo, escrito por el cardenal Stephan Wyszynski, publicado en español en 1958, a fin de mostrar su influencia en los contenidos de Laborem Exercens. Efectivamente, considerando la relación estrecha entre Wyszynski y Wojtyla, conocido luego como Juan Pablo II, resulta de una especial importancia señalar cuánto ha influido el libro del primado polaco en el pensamiento del Papa. El cristianismo promovió la elevación del trabajo humano de conformidad con la dignidad humana, en la cual el trabajo halla las fuentes de su propia dignidad: ser una acción emanada de la inteligencia y de la voluntad humanas. Este es el primer paso para desarrollar la idea de un ethos del trabajo referido a la persona humana en tanto que imagen y semejanza de Dios. El trabajo es uno de los modos en que la persona humana se dirige hacia el pleno desarrollo a través del perfeccionamiento de su naturaleza racional. El significado del trabajo como participación en la creación de Dios es entendido como cooperación en Su obra creadora. El trabajo es también un modo efectivo de aproximación a Dios, como lo demostró Cristo trabajando junto a José, al punto de ser considerado el hijo del carpintero. Antes del pecado original el trabajo aportaba solo satisfacción y alegría, pero con el pecado original aparecieron el esfuerzo y el dolor. Esto se conecta con la consideración del trabajo como camino de santificación y redención para los hombres, aspecto señalado especialmente para mostrar el valor redentor del trabajo humano.

Palabras clave: Trabajo; Dignidad; Creación; Pecado; Redención

On the fortieth anniversary of Laborem Exercens: the spirituality of work

Abstract: This year (2021) Pope Francis beatified Cardinal Stephan Wyszynski on september 12th, two days before Laborem Exercens fortieth anniversary. This essay presents some aspects of the book El espiritu del trabajo (The spirit of work) written by

${ }^{*}$ Recibido: 16/11/2021 - Aprobado: 10/12/2021 
cardinal Wyszynski, published in Spanish in 1958, to show its influence in Laborem Exercens contents. Effectively, considering the close relationship between Wyszynski and Wojtyla, better known as John Paul II, results of a special importance to show how much has influenced the poland primate in the Pope. Christianity brought the real elevation of human work according to human dignity, in which, work finds the sources of its own dignity: being an action produced by human intelligence and will. This is the first step to develop the idea of a work ethos referred to human person as image and resemblance of God. Work contributes to the whole development of human person through the perfecting of rational nature. The meaning of work as participation in God's labour creation is understood as man's cooperation in His creative labour. Work is also an effective way to approach to God, as Christ has shown himself working with Joseph, at the point of being considered the son of the carpenter. Before original sin work provided only satisfaction and joy, but after it, effort and pain appeared. This is connected with the importance of work as a way of sanctification and salvation for men, aspect specially considered in order to show the redemptive value of human work.

Keywords: Work; Dignity; Creation; Sin; Redemption

\section{Introducción}

En 2007 publiqué el fruto de una investigación intitulado Aportes del cardenal Wyszynski en la gestación de Laborem Exercens. El tema de la espiritualidad del trabajo ${ }^{1}$. Este año el Papa Francisco beatificó al cardenal Stephan Wyszynski el 12 de septiembre, providencialmente dos días antes de cumplirse el cuadragésimo aniversario de la encíclica. Esta circunstancia me indujo a reformularlo y actualizarlo para destacar la influencia del libro El espíritu del trabajo, publicado por Wyszynski en 1955, sobre Laborem Exercens, presentada por san Juan Pablo II en Castelgandolfo el 14 de septiembre de 1981. La obra, importante por su propio peso, adquiere mayor relevancia si se la mira desde la perspectiva de la encíclica. Considerando la proximidad y el afecto que manifestaba san Juan Pablo II por quien fuera su primado, resulta de interés reflexionar sobre la vinculación entre el pensamiento de Wojtyla, llamado a la silla de Pedro, y las enseñanzas del Cardenal vertidas tantos años antes. De la lectura de ambos textos infiero que el Papa había rumiado palabra por palabra el libro de Wyszynski, y su pensamiento había calado hondo en la mente del pontífice, al punto de dedicar su primera encíclica social a este tema. Por eso dice Laborem Exercens: "La Iglesia está convencida de que el trabajo constituye una dimensión fundamental de la existencia del hombre" (Juan Pablo II, 1981: $\mathrm{n}^{\circ}$ 4). Son elocuentes las palabras que emplea para referirse a 
la publicación del texto: "Este documento, que había preparado para que fuese publicado el día 15 de mayo pasado, con ocasión del nonagésimo aniversario de la encíclica Rerum Novarum, he podido revisarlo definitivamente sólo después de mi permanencia en el hospital" (Juan Pablo II, 1981: 87). Deduzco que, con el texto ya compuesto y en el silencio del prolongado período de recuperación luego del atentado que sufriera, san Juan Pablo II dedicó preciosos momentos a reflexionar y pulir las enseñanzas que volcaría en el documento.

El trabajo que me propongo ofrecer consiste en una exposición de aquellas cuestiones tratadas por Wyszynski concernientes a la naturaleza del trabajo humano y su relación con la creación, el pecado original y la redención del hombre, para resaltar la trascendencia y profundidad de este texto y destacar los aportes de esta obra respecto de un ethos del trabajo humano. Entiendo el término ethos como "modo de ser" o "carácter". Laborem Exercens lo expresa en estos términos:

En efecto no hay duda de que el trabajo humano tiene un valor ético, el cual está vinculado completa y directamente al hecho de que quien lo lleva a cabo es una persona, un sujeto consciente y libre, es decir, un sujeto que decide de sí mismo (Juan Pablo II, 1981: $\left.n^{\circ} 6\right)$.

Constituyendo el trabajo humano una actividad tan importante en la vida del hombre, la pregunta por el ethos resulta de máximo relieve para determinar su deber-ser. En este sentido hallo apropiadas las siguientes palabras del cardenal Ratzinger: "Lo específico del hombre en cuanto hombre consiste en interrogarse no sobre el 'poder', sino sobre el 'deber' como apertura a la voz de la verdad y de sus exigencias" (Ratzinger, 2005: 164). A este ethos del trabajo, al que me refiero, parece aludir Wyszynski al decir: "Es posible elevar la importancia educativa del trabajo humano, tanto en el terreno particular como en el social" (Wyszynski, 1958: 17).

\section{La obra de Dios y el trabajo de Cristo}

Luego de presentar algunas cuestiones propias del trabajo en el mundo de mediados del siglo XX, cuando Wyszynski escribía su libro, se aboca a responder la siguiente pregunta: ¿qué es el trabajo humano? Para poder hacerlo adecuadamente, reflexiona sobre el trabajo de Dios, si fuera posible hablar de tal modo, y no duda en responder afirmativamente ya que el mismo Cristo así lo ha manifestado: "Mi Padre sigue obrando todavía, y por 
eso obro yo también" (Jn 5, 17). Sus palabras ponen de manifiesto que el Hijo sigue el ejemplo del Padre, ejemplo que comienza en los albores de la creación, en las mismas escenas descriptas por el libro del Génesis que da muestras de la labor incansable del Creador "principio de toda actividad, de todo movimiento, del trabajo" (Wyszynski, 1958: 29). Las palabras del Cardenal resonarán en la encíclica:

Encontramos esta verdad ya al comienzo mismo de la Sagrada Escritura, en el libro del Génesis, donde la misma obra de la creación está presentada bajo la forma de un "trabajo" realizado por Dios durante los "seis días" para "descansar" el séptimo (Juan Pablo II, 1981: $\mathrm{n}^{\circ}$ 25).

A partir de esta descripción de la labor creadora de Dios, Wyszynski invita a que el hombre tenga siempre presente ante sus ojos la visión del acto creador para no sobreestimar los frutos de su trabajo. El ethos que pretende transmitir tiene que ver tanto con la forma de trabajar que percibe -"trabajo previsor, consciente y amoroso de Dios" (Wyszynski, 1958: 32)como con la dependencia del hombre respecto de Dios, con su contingencia, con su limitación, con su rol de lugarteniente en la obra creadora que Dios ha iniciado y el hombre debe continuar: "El hombre, en efecto, no crea nada, no hace más que elaborar los dones creados por Dios" (Wyszynski, 1958: 32). De aquí se desprende ya una sugerencia para un ethos del trabajo humano, un deber-ser a semejanza del acto creador: previsor, consciente y amoroso. Previsión y conciencia denotan la participación del hombre, que asume las consecuencias sopesando los posibles efectos de su obrar, velando por el respeto hacia el mundo creado y sus leyes, y considerando el derecho de los demás a gozar también ellos de los dones de la creación. El trabajo amoroso refiere a una acción que, a semejanza de la obra creadora, denota donación, entrega de sí para el mejor fruto, para que la obra realizada sea perfecta, plenamente conforme a su naturaleza. Al leer el texto no se puede dejar de pensar en la virtud de la prudencia, y lo mismo advierte el Cardenal al referirse al plan de Dios: "Sin embargo, el cumplimiento detallado de su plan lo confía al hombre, ser consciente, que ha de cooperar, mediante su prudencia, a llevar la creación entera a la finalidad establecida por el Hacedor" (Wyszynski, 1958: 33).

Luego de exponer sobre este trabajo del Creador, Wyszynski explica de inmediato la forma en que Cristo continúa con la obra del Padre, su dedicación al trabajo manual, colaborando con José, su apelativo de "obrero" o "artesano" impuesto por sus coterráneos. Presenta también el 
valioso análisis de las dos fuentes ejemplificadoras que nutren al Señor, la del Padre creador y la del padre adoptivo. Laborem Exercens se hará eco de estas reflexiones diciendo:

\begin{abstract}
Esta verdad, según la cual a través del trabajo el hombre participa en la obra de Dios mismo, su Creador, ha sido particularmente puesta de relieve por Jesucristo, aquel Jesús ante el que muchos de sus primeros oyentes en Nazaret permanecían estupefactos y decían; “¿De dónde le vienen a éste tales cosas, y qué sabiduría es ésta que le ha sido dada? ... ¿No es acaso el carpintero?”. En efecto, Jesús no sólo lo anunciaba, sino que ante todo, cumplía con el trabajo el "evangelio" confiado a él, la palabra de la Sabiduría eterna. Por consiguiente, esto era también el "evangelio del trabajo", pues el que lo proclamaba, él mismo era hombre del trabajo, del trabajo artesano al igual que José de Nazaret (Juan Pablo II, 1981: $\mathrm{n}^{\circ}$ 26).
\end{abstract}

Llamativamente Wyszynski repara también en una escena singular: cuando Cristo resucita, se presenta a sus discípulos mientras ellos están trabajando entre barcas y redes; han regresado a sus faenas. Entusiasma la conclusión del primado polaco al hablar del trabajo de esos pescadores: "Han vuelto tranquilamente a sus tareas y no se les ha ocurrido nada que no fuera el viejo trabajo: lo llevaban demasiado dentro del corazón, y los atraía con demasiada fuerza" (Wyszynski, 1958: 37), palabras que seducen para reflexionar que es en medio de ese trabajo donde los discípulos hallan nuevamente a Cristo. Él les sale al encuentro en medio de sus ocupaciones cotidianas y es ahí donde lo ven. De estos pescadores de peces, hombres acostumbrados a las dificultades, a las tempestades, a los fracasos, en fin, hombres hechos en la perseverancia y la paciencia, hará Dios pescadores de hombres.

\title{
III. Concepción cristiana del trabajo
}

En esta relación entre el trabajo físico y el apostólico, halla Wyszynski el punto de arranque y sustento para el respeto que el pensamiento cristiano ha mostrado siempre hacia el trabajo humano. Es conocido el hecho de que san Pablo hiciera expresa mención de que trabajaba con sus manos para no resultar gravoso a sus comunidades. Desde entonces aparece una clara distinción entre la concepción cristiana del trabajo y la concepción pagana; esta se caracterizó por menospreciar y hasta despreciar cualquier tipo de trabajo, aun el artístico. En el mismo sentido señala acertadamente el Cardenal: "El cristianismo acabó también con este error, haciendo real y 
efectiva la liberación y dignificación del trabajo humano" (Wyszynski, 1958: 38). Aquí pone al trabajo en su real relación con la naturaleza y dignidad del hombre, admitiendo que la dignidad del trabajo procede de ser una acción humana, un acto deliberado del hombre, donde juega su inteligencia y voluntad y, por ende, expresa de ese modo su dignidad, sustentada en ser específicamente imagen y semejanza de Dios gracias a su dimensión espiritual. En esa línea se expresa Laborem Exercens: "Las fuentes de la dignidad del trabajo deben buscarse principalmente no en su dimensión objetiva, sino en su dimensión subjetiva" (Juan Pablo II, 1981: $\mathrm{n}^{\circ}$ 6). Y refuerza esta idea al decir:

Suponiendo que algunos trabajos realizados por los hombres puedan tener un valor objetivo más o menos grande, sin embargo queremos poner en evidencia que cada uno de ellos se mide sobre todo con el metro de la dignidad del sujeto mismo del trabajo, o sea de la persona, del hombre que lo realiza (Juan Pablo II, 1981: $\left.n^{\circ} 6\right)$.

Es absoluta la sintonía del Papa con lo escrito por Wyszynski tantos años antes: "El valor, pues, de la obra humana no depende de su objeto, sino de cómo se realiza, del grado de amor y sumisión al Dios de la bondad que lleva consigo" (Wyszynski, 1958: 90). Desde nuestra visión del hombre, no decimos que el trabajo dignifique al hombre, pues significaría admitir que quienes trabajan son más dignos que quienes no lo hacen; decimos en cambio que el trabajo es digno porque lo realiza un hombre cuya dignidad proviene de ser hijo de Dios, creado a su imagen y semejanza, dotado de una naturaleza racional, de inteligencia y voluntad.

Resulta de interés observar que en 1954 aparecía, una obra, L'enseignement social de l'Eglise de Jean Villain, jesuita francés de reconocida experiencia en el campo social, en la que afirmaba:

Nosotros estamos aquí en las antípodas del pensamiento socialista puro; para él, el hombre tiene una dignidad porque trabaja; la fuente de su dignidad está en su trabajo o mejor en la obra realizada. Nosotros decimos, por el contrario, que es el hombre el que da una dignidad al trabajo; la fuente de la dignidad del trabajo humano está en el hombre (Villain, 1957: 188).

El trabajo es, en nuestra visión cristiana, expresión y testimonio de la dignidad del hombre, pues en la actividad laboral el hombre pone de sí las cualidades que el Creador le concedió para dominar la tierra, para 
transformar la creación, perfeccionándola, perfeccionándose también a sí mismo y colaborando en el desarrollo de sus hermanos. Esto lo expresa magníficamente san Juan Pablo II: "Y [el trabajo] es no sólo un bien 'útil' o 'para disfrutar', sino un bien 'digno', es decir, que corresponde a la dignidad del hombre, un bien que expresa esta dignidad y la aumenta" (Juan Pablo II, 1981: $n^{\circ}$ 9). ¿Qué significa que la aumenta? Creo que la respuesta a esta pregunta la da con gran precisión el Papa Francisco:

Pero queremos más todavía, nuestro sueño vuela más alto. No hablamos sólo de asegurar a todos la comida, o un "decoroso sustento" sino de que tengan "prosperidad sin exceptuar bien alguno" (Mater et Magistra $\mathrm{N}^{\circ}$ 3). Esto implica educación, acceso al cuidado de la salud y especialmente trabajo, porque en el trabajo libre, creativo participativo y solidario, el ser humano expresa y acrecienta la dignidad de su vida (Francisco, 2013: $\mathrm{n}^{\circ}$ 192).

La conexión entre el pensamiento de san Juan Pablo II y el de Francisco la hallo en "el ser humano expresa y acrecienta la dignidad de su vida”. No es la dignidad esencial del hombre, creado a imagen y semejanza de Dios, la que aumenta mediante el trabajo, sino la dignidad de su dimensión existencial, la de su vida, como acertadamente lo señala Evangelii Gaudium.

Wyszynski destaca el enaltecimiento del trabajo:

Es más, el cristianismo vino a subrayar la importancia de las relaciones existentes entre la tarea espiritual y la física, y lo hizo sobre todo a través de la vida monacal, asociación íntima de la contemplación más elevada con el trabajo manual (Wyszynski, 1958: 39).

En directa alusión a la consigna benedictina ora et labora, el reza y trabaja con el que los monjes proclaman su agradecimiento a Dios por las maravillas de la creación y la transforman en servicio a los hombres, generando una estrecha relación entre su vocación contemplativa y actividades temporales como la agricultura, la ganadería, las artesanías, etc. El trabajo ya no es propio de esclavos sino de seres libres, capaces de honrar a Dios mediante su ofrecimiento, logrando así un camino de santificación personal. La concepción cristiana no es ajena a la tradición del Antiguo Testamento, pues frente a las duras palabras del Génesis: "Con el sudor de tu rostro comerás el pan" (Gn 3, 19), los salmos ofrecen una visión distinta, 
más positiva, de la misma fatiga que parece enajenar al trabajo: "Porque comerás del trabajo de tus manos, serás feliz y bienaventurado” (Sal 128, 2).

\section{Trabajo y perfección humana}

Cuando Wyszynski se refiere al trabajo en tanto que necesidad de la naturaleza humana, para dedicar un capítulo de su libro a esta cuestión, comienza con este párrafo:

El inspirado autor del salmo 104 habla de dos leyes: la ley de la noche y la ley del día. Dice así de la primera: "Tú tiendes las tinieblas y se hace noche, y en ella corretean todas las bestias salvajes..., pidiendo así a Dios su alimento". Mas he aquí que llega la ley del día: "Sale el hombre a sus labores, a sus haciendas, hasta la tarde". La ley del día es la ley del trabajo del hombre. El mundo animal, escondiéndose en sus madrigueras, deja el campo al ser consciente. Es una invitación al trabajo humano, la creación de las condiciones que necesita. La ley del día es, a la vez, la obligación del día. El trabajo es, pues, la obligación del hombre, y esta obligación nace de las necesidades vitales mismas, así como del papel primordial que para la plenitud de la personalidad humana desempeña el trabajo (Wyszynski, 1958: 40).

Aunque algo extensa, la cita merece ser transcripta pues permite apreciar el pensamiento del autor desde su concepción antropológica. Cabría preguntarse por qué esta oposición entre ley de la noche y ley del día. La clave está en el mismo Evangelio y solo desde ahí puede comprenderse. Las obras de la noche son las que degradan al hombre, las que frenan su desarrollo, las que conspiran contra el progreso y el crecimiento del hombre en cuanto persona humana; las obras del día son las del hombre responsable de su propio destino y del de sus hermanos, aquellas que reflejan la imagen y semejanza del hombre respecto de Dios. Aun siendo una metáfora, podría decirse que las obras de la noche son las de los seres no racionales, la racionalidad campea durante el día. Deseo destacar un término empleado en el texto citado que resulta muy apropiado para comprender acabadamente el ethos del trabajo; me refiero a la palabra "consciente" que seguramente fue incorporada con plena deliberación por el autor. Si bien parece sinónimo de "racional" en oposición al mundo animal del que habla antes, la expresión "consciente" tiene más fuerza al referirse al trabajo, porque no solo denota la racionalidad esencial de la persona humana, sino la plena voluntad de hacer lo que se está haciendo, con total compromiso de las potencias humanas, asumiendo las reglas del obrar 
concreto para alcanzar la perfección de la obra realizada y para aproximarse también el hombre a su propia perfección, aunque relativa como todo lo humano.

Pero Wyszynski no se detiene ahí, da un paso más, vinculando racionalidad con obligación. ¿Con qué obligación? Con aquella que emana de esa naturaleza racional, precisamente, pues concierne a la naturaleza propia del hombre. Si bien en lo físico el hombre presenta las mismas limitaciones que los animales, la dimensión espiritual, que lo asemeja a Dios, le permite elevarse por sobre esas limitaciones y expandir su inteligencia y el dominio de su voluntad para crecer y desarrollarse. Por lo tanto, la obligación a la que se refiere es la obligación moral respecto de su desarrollo, de la cual ningún hombre puede eximirse y en la cual tampoco puede ser sustituido. Esas son las obras del día, las que todos pueden apreciar y admirar, las obras meritorias que el trabajo comprende en sus dos aspectos: corporal, aportando los bienes para su subsistencia; espiritual, dando ocasión para el desarrollo de la inteligencia y de la voluntad. Por eso afirma de inmediato: "Sin el trabajo no se puede sostener la vida ni alcanzar el pleno desarrollo de la personalidad. Él es, en efecto, quien mantiene en nosotros el don de Dios, la vida, satisface dignamente sus posibilidades y perfecciona nuestra naturaleza consciente" (Wyszynski, 1958: 40-41). Obsérvese el modo sutil con que el Cardenal eleva al trabajo por encima de su dimensión material, pues al sostenimiento de la vida (dimensión corporal) añade el pleno desarrollo de la personalidad (dimensión espiritual) y de inmediato lo vincula a la vida como don de Dios (dimensión trascendente). Esta nueva condición de ser consciente se aplica a la forma de trabajar, mas también al hecho de ser capaces de ver la vida como don de Dios, vida que nos ha sido dada para enriquecerla, para hacerla plena: "El trabajo constituye uno de los medios puestos a nuestro alcance para el progreso espiritual. Su ejecución debe llevarse de manera que el hombre se perfeccione, no sólo en eficiencia física, sino también en eficacia moral" (Wyszynski, 1958: 49). Obsérvese que no dice que el trabajo perfeccione al hombre sino que dice acertadamente que el hombre "se perfeccione", porque el perfeccionamiento no le viene al hombre del exterior sino de las disposiciones con que enfrenta lo que viene del exterior. Aun el trabajo más duro y árido puede ser transformado en fuente de enriquecimiento integral de la persona humana si es llevado a cabo con un sentido creador y formativo, con un compromiso consciente y eficaz de su inteligencia y voluntad por lograr el cometido. 
Como Wyszynski intuye que no puede hablar de la naturaleza del trabajo sin bucear en sus orígenes, refiere al relato del Génesis en estos términos:

Fue entonces cuando, al poner al hombre en el paraíso, Dios le ordenó que lo cultivara y lo cuidara (Gn 2,15). No hubo, pues, que esperar a la caída para encontrarse con la obligación de trabajar; el mismo paraíso hubo de ser cultivado (Wyszynski, 1958: 41).

Tal referencia le permite disociar el trabajo del castigo merecido por el pecado, por el cual le fue añadida la fatiga: "Pero a la simple obligación anterior viene a añadirse un esfuerzo especial y desconocido, consecuencia de la mácula de la culpa en la inteligencia y en la voluntad" (Wyszynski, 1958: 42). Muestra así, por un lado, la obligación de trabajar para lograr su perfección en virtud de la estrecha relación entre trabajo y naturaleza consciente; por otro, los efectos del pecado sobre la inteligencia y la voluntad. Por ese motivo, la próxima cuestión que plantea es la del trabajo en su relación con la vocación, antes de lo cual, para que no quede una impresión negativa del trabajo, afirma: "En el trabajo hay que ver, por consiguiente, una noble vocación a colaborar en el cumplimiento del plan divino; no un castigo, sino una prueba de confianza en el hombre" (Wyszynski, 1958: 42). Definiendo al trabajo como una vocación, más aún como una noble vocación, y despejando de él aquella visión escéptica que lo vincula exclusivamente al castigo, el Cardenal renueva el rostro del trabajo y lo inserta en una genuina antropología que refleja que el hombre continúa la obra creadora de Dios gracias a que el Creador depositó previamente en él toda su confianza.

Llama la atención un aspecto del trabajo que señala Wyszynski que, creo, no ha sido suficientemente elaborado y explorado en la consideración del ethos:

Basta una simple ojeada en torno nuestro para descubrir los frutos de la actividad humana, para comprobar la conveniencia y utilidad de sus esfuerzos, para que resulte evidente que el trabajo tiende a dar a las cosas un valor nuevo gracias al cual se nos hacen útiles. Esa utilidad constituirá luego el aliciente que nos empuje a seguir trabajando, y la prueba del valor de nuestra obra, la posibilidad, gracias al trabajo, de satisfacer el hambre y la sed, de vestirse, de levantar un techo sobre nuestra cabeza (Wyszynski, 1958: 43). 
Como bien lo expresa el autor, la utilidad corresponde tanto a bienes de consumo, que son los que satisfacen necesidades primarias -hambre, sed, vestido y otras- como a bienes durables -techo- pero también a otros bienes durables, como los que hacen posible, o al menos facilitan el trabajo: la técnica, de la que luego me ocuparé.

En el texto transcripto, la utilidad se relaciona con la causa eficiente del trabajo al decir que ejercerá el rol de aliciente para continuar trabajando, y también con la causa final en tanto que búsqueda de aquellos bienes que el hombre necesita para su subsistencia. Podrían distinguirse aquí dos aspectos que hacen al ethos de la acción laboral: el finis operis (el fin de la acción propiamente dicha, lo que se hace); el finis operantis (el fin del agente que trabaja, donde ocupa un lugar importante la satisfacción de necesidades). En este sentido, el Cardenal no deja pasar la ocasión para decir de inmediato que

no son sólo la boca y el estómago los que obligan al hombre a trabajar: impúlsanos a ello toda nuestra naturaleza consciente, ya que el trabajo debe conducir a la plenitud de desarrollo de nuestras potencias espirituales y al perfeccionamiento del individuo (Wyszynski, 1958: 43).

Menciona concretamente las "potencias espirituales", es decir, aquellas potencias específicamente humanas como son la inteligencia y voluntad. Como no podía ser de otra manera, Laborem Exercens recoge y sintetiza de esta manera lo dicho por Wyszynski:

El trabajo es un bien del hombre -es un bien de su humanidadporque mediante el trabajo el hombre no sólo transforma la naturaleza adaptándola a las propias necesidades, sino que se realiza a sí mismo como hombre, es más, en un cierto sentido "se hace más hombre" (Juan Pablo II, 1981: nº 9).

Ya que hablamos de utilidad, no quiero dejar pasar un párrafo especialmente significativo del primado polaco: "Con el trabajo llegamos a perfeccionar la cosa, la obra efectuada, puesto que intentamos darle una utilidad nueva, un nuevo valor; sólo se justifica aquella actividad que confiera al objeto una nueva utilidad, sólo así tiene sentido" (Wyszynski, 1958: 48). Advierto aquí una idea cara al pensamiento de la escolástica hispana desarrollada por Vitoria, Soto, Azpilcueta, Albornoz, García, Molina y muchos otros: que el valor de las cosas depende de la utilidad que brindan y cuando el hombre transforma una cosa en algo mejor, aumenta su valor, 
siendo este un sentido primordial del trabajo, transformar las cosas para que satisfagan necesidades insatisfechas, o para que mejoren el grado de satisfacción de necesidades parcialmente cubiertas. Señala Wyszynski que la actividad se justifica solo si le confiere a la cosa una nueva utilidad, es decir, si esa actividad es efectivamente transformadora, y agrega de modo contundente: "sólo así tiene sentido".

Me detengo ahora en las siguientes palabras del texto porque hallo en ellas el gozne entre la dimensión objetiva del trabajo y su dimensión subjetiva, como las denomina Laborem Exercens: "Mediante el enriquecimiento de la cosa con valores nuevos, el trabajo se convierte en fuente de bienestar, de riqueza nacional. Todo cuanto nos rodea ha de enriquecerse, por voluntad de Dios, con valores nuevos: 'Haceos la tierra sumisa..." (Wyszynski, 1958: 48). En la expresión "mediante el enriquecimiento de la cosa con valores nuevos" Wyszynski alude a una transformación tal que cambie esa cosa en otra, y ve aquí un enaltecimiento óntico pues la cosa se torna mejor, más perfecta; pero también un incremento valorativo, porque adquiere más valor gracias a la mayor utilidad adquirida por la transformación producida. He aquí la dimensión objetiva apreciada por la dimensión subjetiva en la asignación de valor; produce un enriquecimiento material del hombre que ha logrado esa transformación, ya que cuando la cosa logra mayor valor, él posee entonces algo que vale más. Pero cuando el autor dice que "el trabajo se convierte en fuente de bienestar, de riqueza nacional" está aludiendo a otra riqueza, que es la cantidad de bienes disponibles para la sociedad, alcanzando por ende un sentido social y comunitario. San Juan Pablo II también contempla este aspecto al redactar su encíclica:

Todo esto hace que el hombre concilie su más profunda identidad humana con la pertenencia a la nación y entienda también su trabajo como incremento del bien común elaborado juntamente con sus compatriotas, dándose así cuenta de que por este camino el trabajo sirve para multiplicar el patrimonio de toda la familia humana, de todos los hombres que viven en el mundo (Juan Pablo II, 1981: $\left.\mathrm{n}^{\circ} 10\right)$.

En este ethos se vinculan estrechamente la dimensión corporal mediante la cual el hombre ejecuta sus tareas, no solo el trabajo manual sino también el trabajo intelectual, disponiendo para ello sus facultades- y la dimensión espiritual, pues el trabajo debe ser guiado por la inteligencia y la voluntad hacia la esfera de la perfección total del hombre, donde gravitan 
sus necesidades pero también sus gustos, sus deseos, sus anhelos, sus aspiraciones. Es en la fecunda interrelación y en el pleno compromiso de todas las facultades humanas, físicas y espirituales donde halla Wyszynski la concreción del "tipo ideal del hombre trabajador" (Wyszynski, 1958: 45). Todo trabajo requiere la participación de facultades físicas y espirituales, aunque la participación de unas y otras sea diferente conforme a la naturaleza particular de cada tarea. Aquí se halla otra relación inmediata entre el aspecto objetivo de la labor y el aspecto subjetivo, donde las exigencias son puestas por la dimensión objetiva a la que la dimensión subjetiva debe someterse para lograr la perfección de la obra. Se advierte que no puede haber perfección del sujeto si no se procura la perfección de la obra. Nuevamente, ambas dimensiones, subjetiva y objetiva, se hallan imbricadas en total armonía para que cuando el hombre respete las normas de perfección de cualquier tipo de trabajo, también encuentre en el deberser del trabajo, un camino de perfección de su propia personalidad. Este respeto por las normas de la tarea no significa el sometimiento del hombre a la técnica. Toda vez que se ha pretendido tal cosa, en aras de una organización científica del trabajo, lo que se ha logrado ha sido despersonalizar el trabajo y convertir al hombre en un mero instrumento. El trabajo pierde así las características espirituales que son las que procuran su personalización en la tarea. Wyszynski plantea una paradoja al sugerir que la técnica, fruto de la racionalidad del hombre, se convirtió entonces en el peor enemigo de tal racionalidad al desplazar a la inteligencia en el ejercicio laboral, provocando la monotonía y el desinterés. Allí donde no concurra la inteligencia como expresión de la creatividad humana, se verá lesionada la colaboración del hombre en la obra creadora de Dios como vocación personal. Por eso el Cardenal destaca el lugar que debe ocupar la acción inteligente en el desarrollo laboral:

El trabajo debe reservar siempre un sitio para el pensamiento, porque si nos privamos de este nos empequeñecemos nosotros mismos y empobrecemos a la sociedad, en la que los hombres van perdiendo el hábito de usar la inteligencia en su vida cotidiana. El mundo acaba convirtiéndose en una sociedad de autómatas. Los hombres pierden la conciencia de formar una comunidad (Wyszynski, 1958: 46).

La cultura del trabajo debe permitir formar personas comprometidas con su tarea y con la sociedad, conscientes de configurar una comunidad, que no es un simple amontonamiento de hombres sino un conjunto de personas unidas por una tradición que constituye su pasado, y por ideales y 
valores que le señalan un porvenir. La expresión "autómatas" con claro sentido negativo alude a un grupo de "hombres masa", es decir sin discernimiento personal, arrebañados y no mancomunados en el esfuerzo. Laborem Exercens refleja también la misma preocupación haciéndose eco de las reflexiones que Wyszynski plantea:

Entendida aquí no como capacidad o aptitud para el trabajo, sino como un conjunto de instrumentos de los que el hombre se vale en su trabajo; la técnica es indudablemente una aliada del hombre. Ella le facilita el trabajo, lo perfecciona, lo acelera y lo multiplica. Ella fomenta el aumento de la cantidad de productos del trabajo y perfecciona incluso la calidad de muchos de ellos. Es un hecho, por otra parte, que a veces, la técnica puede transformarse de aliada en adversaria del hombre, como cuando la mecanización del trabajo "suplanta" al hombre, quitándole toda satisfacción personal y el estímulo a la creatividad y responsabilidad; cuando quita el puesto de trabajo a muchos trabajadores antes ocupados, o cuando mediante la exaltación de la máquina reduce al hombre a ser su esclavo (Juan Pablo II, 1981: $\mathrm{n}^{\circ}$ 5).

El primado señala los caminos a seguir para construir una cultura del trabajo, signada por el ethos particular que le impone la acción plenamente humana: un trabajo bien organizado debe permitir siempre su plena comprensión: "La inteligencia y la voluntad deben poder sacar algún provecho de él" (Wyszynski, 1958: 46); y podríamos agregar, sin traicionar su pensamiento, que sin esa condición no hay verdadero desarrollo humano en el trabajo ejecutado. Por eso señala:

El primer beneficiario de un trabajo entendido de esta manera es el mismo trabajador. Y no porque cobre un jornal, sino gracias a que el trabajo, inseparablemente ligado a su persona, forma y desarrolla su inteligencia, voluntad y sentimientos, y se convierte en fuente de virtudes y eficiencias morales, físicas e intelectuales (Wyszynski, 1958: 47).

Deseo retomar ahora lo que dije antes: el trabajo presenta una dimensión objetiva, un "qué" (causa material) lo que el hombre hace, su labor transformadora, que repercute directamente sobre la creación, sobre las cosas en las que trabaja. Así enriquece a la propia creación dotando a las cosas de un nuevo status. Pero también el hombre tiene un "cómo" (causa formal), un "por qué" (causa eficiente) y un "para qué" (causa final) que representan la dimensión subjetiva del trabajo: las disposiciones con que lo realiza, los motivos que lo impulsan a la actividad laboral y los fines que 
persigue. Según sea esta dimensión subjetiva, será el grado de perfeccionamiento que el hombre logre en la acción emprendida. Es decir que el enriquecimiento se manifiesta en tres aspectos estrechamente relacionados: el enriquecimiento en la cosa, que significa también enriquecimiento de la creación; el enriquecimiento material y espiritual del hombre que trabaja y, finalmente, el enriquecimiento de la sociedad porque dispone de cosas que le proveen mayor satisfacción a sus necesidades. Cuando Wyszynski habla del enriquecimiento de la creación dice "todo lo que nos rodea ha de enriquecerse" y agrega "por voluntad de Dios" (Wyszynski, 1958: 48), reconociendo que todas las cosas son llamadas a adquirir un mayor valor, un mayor grado de perfección. En el texto que vengo analizando engarza el autor la tridimensionalidad de la persona humana, mostrando su triple relación con Dios, con la creación y consigo mismo, pues la transformación de la creación mediante la actividad laboral no solo es deseada por el Creador, en su mandato "someted la tierra", sino que constituye también una forma de rendirle culto uniéndose a la acción creadora iniciada por Dios. El hombre expresa de ese modo su imagen y semejanza, haciéndose él también creador, no mediante una creación ex nihilo sino a través de la transformación que aplica a la creación donada por Dios. Basta observar la cantidad de bienes de los que dispone el hombre contemporáneo respecto de aquellos de que disponían sus antepasados,

para comprobar que efectivamente el hombre va cumpliendo paulatinamente con el "someted la tierra" más allá de sus fracasos y sus pecados. Cuando el hombre comprende esto, se adentra en la dimensión trascendente.

\section{Trabajo y solidaridad}

En la consideración del ethos del trabajo no puede descuidarse su dimensión social como forma de vinculación para un desarrollo integral que alcance a todos los hombres y a todo el hombre. Por eso, Wyszynski introduce luego un capítulo dedicado al trabajo como obligación social: "Al igual que cualquier otra actividad humana, el trabajo refleja en sí el carácter doble de la personalidad; va enderezado a fines propios y, al mismo tiempo los sobrepasa, mira al prójimo; además de personal, es social” (Wyszynski, 1958: 51). Desde el momento en que el hombre no puede abarcar la totalidad de los procesos que requiere la producción de bienes, se relaciona con otros hombres, se vincula con ellos y forma equipos de trabajo. Así, el hombre no permanece aislado ni encerrado en sí mismo, sino que procura 
una apertura a los demás para compartir sus habilidades y conocimientos en la tarea común.

Es necesario asumir también la dimensión temporal de la obra conjunta, y reflexionar sobre la perspectiva de una solidaridad vertical que atraviesa la historia de los hombres que habitan en diversas etapas de la evolución de la humanidad, para generar el progreso técnico y el desarrollo de una generación respecto de otra. Dice el Cardenal: "Toda labor humana es continuación de otra anterior, es, pues, origen de un vínculo histórico; la obra hecha pone en relación el pasado con el futuro" (Wyszynski, 1958: 52). Más adelante agrega: "Trabajar es tender los hombres hacia los hombres..." (Wyszynski, 1958: 54) y esta tensión de unos hacia otros gracias al trabajo le sirve al autor para explicar por qué el trabajo es creador de la sociedad humana: "Porque nos enseña el amor y la caridad, el sentido de la dependencia y de la humildad, y porque nos empuja a la utilidad mutua..." (Wyszynski, 1958: 55). Ve en el trabajo una forma de enriquecer el amor y la caridad entre los hombres, no solo por el hecho de compartir saberes y habilidades que entrelazan la tarea común, sino también porque los frutos de ese trabajo que mancomuna esfuerzos pueden destinarse a quienes no tienen posibilidades de trabajar, hacia los miembros más desprotegidos y vulnerables de la comunidad. Este pensamiento enlaza con la tradición cristiana de socorrer a los débiles y a los necesitados, aunque no puedan trabajar ni ganarse el sustento por sus propios medios; ellos también son hijos de Dios, iguales en dignidad. De modo rotundo, el Cardenal afirma:

\begin{abstract}
Este concepto confiere al trabajo humano su carácter más elevado, lo limpia de egoísmo, de afán de lucro, de espíritu materialista y rastrero. Nuestra acción debe llevar consigo el espíritu de caridad, de sacrificio, de desinterés, la voluntad de servir a los imposibilitados, a los pobres, a los huérfanos, a quienes el esfuerzo y la faena resultan imposibles, y, en particular, a los enfermos (Wyszynski, 1958: 61-62).
\end{abstract}

\title{
VI. Trabajo y creación
}

Hay que destacar un enfoque relevante de la relación entre el trabajo y la colaboración del hombre con la obra creadora de Dios: el vínculo que se robustece a partir del cumplimiento de los designios divinos: "La labor cumplida en espíritu de sumisión a Dios, de acuerdo con los planes divinos, lleva al hombre a la amistad de Dios" (Wyszynski, 1958: 90). Agrega el autor más adelante: 
Junto con la vida espiritual, la vida activa es uno de los medios más eficaces de acercarnos a Dios. ¿Acaso no ha querido Él hacer de la creación el primer testigo de su existencia, la primera voz que le dice al hombre: "Dios existe"? Suponiendo que no hubiera revelación ni magisterio de la Iglesia, la creación daría testimonio del Creador. Cuanto más cerca están de la naturaleza, más sienten los hombres la proximidad del cielo (Wyszynski, 1958: 92).

En íntima conexión con lo planteado por el primado polaco dice el Papa en su encíclica:

En la palabra de la divina revelación está inscrita muy profundamente esta verdad fundamental, que el hombre, creado a imagen de Dios, mediante su trabajo participa en la obra del Creador, y según la medida de sus propias posibilidades, en cierto sentido, continúa desarrollándola y la completa, avanzando cada vez más en el descubrimiento de los recursos y de los valores encerrados en todo lo creado (Juan Pablo II, 1981: ${ }^{\circ}$ 25).

Percibimos entonces la importancia que tiene el trabajo en la relación del hombre con Dios. Empleando el término "amistad" para referirse a esta especial forma de relación, que podría también recibir el nombre de "alianza", vincula estas ideas con aquellas palabras de Cristo: "Ya no os llamo siervos, porque el siervo no sabe lo que hace su señor, pero os digo amigos, porque todo lo que oí de mi Padre os lo he dado a conocer (Jn 15, 15)" (Wyszynski, 1958: 90-91). Wyszynski sostiene que a través del trabajo el hombre conoce mejor a Dios, logra un conocimiento más profundo de Él en el sentimiento de dependencia y en el despliegue de sus fuerzas físicas e intelectuales. Es en la sumisión de nuestra inteligencia y voluntad, en la obediencia a las leyes de la creación por Él estipuladas, donde el hombre tiene una ocasión de apreciar el amor que Dios le profesa. El trabajo es entonces un lugar de encuentro con la bondad y la misericordia divinas. Cuando se logra un trabajo de esta calidad espiritual, se alcanza la cima de la vida laboral, la plenitud de unión con la obra creadora de Dios, pues "es una participación en la acción creadora, en la Providencia, en el quehacer inconmensurable por el que Dios lo sostiene todo en el ser, por obra de $\mathrm{Su}$ amor" (Wyszynski, 1958: 93-94). Nuevamente, el primado aclara aquí que el hombre no crea nada en sentido estricto, pero mediante su trabajo logra que las cosas que Dios ha creado alcancen su perfección en relación con el destino para el que fueron creadas. Concreta luego su pensamiento con profundas palabras impregnadas del amor de Dios: "Es voluntad suprema que el ser consciente intervenga en la riqueza natural para ordenarla de 
acuerdo con sus necesidades. Dios necesita las manos, las piernas humanas para llevar la creación a la perfección que Él mismo se propuso" (Wyszynski, 1958: 94). Con esta idea de la necesidad que Dios tiene del hombre, quiere resaltar no una necesidad real de Dios sino una necesidad metafórica, originada en un deseo suyo nacido en el mismo momento de la creación del hombre, al disponer el "para quién" y el "para qué" de la creación, concretados en aquel "someted la tierra". Esto va de la mano con el concepto de amistad ya presentado que alude a la alianza que entabló Dios con el hombre desde el mismo Génesis.

Wyszynski culmina el desarrollo que viene realizando entre trabajo humano y amor al Creador, diciendo:

A veces, nos olvidamos de esa ley de colaboración amorosa con el Hacedor y no advertimos que estamos cumpliendo un acto de amor hacia Él, que, en cierto sentido, completamos -permítasenos la expresión- esa "insuficiencia" divina. Un poco de atención a nosotros mismos bastaría para orientar nuestras potencias espirituales y físicas hacia la colaboración con Dios (Wyszynski, 1958: 94).

En este párrafo sobresale el concepto de la "insuficiencia de Dios" escrita con obvio pudor por parte del autor, porque creo que pone de manifiesto una realidad: nuestro olvido de la condición de hijos, ante todo, pero también de lugartenientes frente a la creación. Y no porque no asumamos el rol de transformadores de la realidad, que sí lo hacemos, sino porque lo que no asumimos es la paternidad de Dios, providente y amorosa, que llega al extremo de depositar su confianza en lo que el hombre haga de sí mismo en esta creación, y de lo que haga también de esta creación salida de sus manos. Aunque el final del texto parezca contradecir lo que dice antes, no es así, por eso me parece importante analizarlo. Dice "un poco de atención a nosotros mismos", pero antes alude a la "insuficiencia divina". ¿A quién hay que atender, quién padece de la insuficiencia? A juzgar por la primera parte del párrafo, es a Dios a quien hay que atender, pero si nos atenemos a la segunda parte, es a nosotros mismos a quienes debemos prestar atención. Este es el sentido que, creo yo, debe darse al texto: la insuficiencia divina a la que se refiere es semejante a aquella insuficiencia que finge cualquier padre cuando quiere que su hijo le ayude en alguna tarea, no porque el padre lo necesite, sino porque como padre quiere que su hijo se desarrolle, que sea capaz de hacer cosas; y por eso celebra que el niño lo haga, y le dirá cosas como "no habría podido hacerlo sin ti" para 
aumentar la autoestima del niño, su confianza en sí mismo. Creo que es de este modo como debe interpretarse la insuficiencia divina de la que habla. No es Dios el que se perfecciona cuando el hombre cumple el mandato dado, sino el mismo hombre que, sometiéndose a la ley de Dios, logra su mayor desarrollo.

\section{Trabajo y pecado original}

Aun cuando mediante el trabajo el hombre logra un mayor grado de perfección personal y social, y con ello la actividad se constituye en fuente de gozo y alegría, de satisfacción y plenitud, también presenta su lado oscuro, pues no es menos cierto que simultáneamente acarrea sacrificios, fatigas y frustraciones. Wyszynski se pregunta sobre el porqué de este misterio, y responde:

Para aclarar este misterio, es menester considerar el trabajo desde el ángulo de la fe. Ésta nos enseña que, antes del pecado original, el trabajo constituía para el hombre alegría pura; el esfuerzo y la fatiga eran desconocidos antes de Adán. Fue el pecado el que añadió al trabajo la condición de obligación, de peso, de sudorosa fatiga, según la sentencia: "Maldita será la tierra por tu causa; con fatiga te alimentarás de ella todos los días de tu vida; espinas y abrojos te germinarán y comerás hierba del campo; con el sudor de tu rostro comerás pan" (Gn 3, 17-19) (Wyszynski, 1958: 121122).

Laborem Exercens no podía eludir una cuestión tan importante como esta, y la aborda en estos términos:

La intención fundamental y primordial de Dios respecto del hombre, que Él "creó a su semejanza, a su imagen", no ha sido revocada ni anulada ni siquiera cuando el hombre, después de haber roto la alianza original con Dios, oyó las palabras: "Con el sudor de tu rostro comerás el pan". Estas palabras se refieren a la fatiga a veces pesada, que desde entonces acompaña al trabajo humano; pero no cambian el hecho de que éste es el camino por el que el hombre realiza el "dominio" que le es propio sobre el mundo visible "sometiendo" la tierra (Juan Pablo II, 1981: $\mathrm{n}^{\circ}$ 9).

Luego de remitir a la revelación para comprender por qué el trabajo es, además de fuente de alegría, fuente de dolor, señala que, en tanto que acto humano bueno, se convierte en manantial de virtudes que, aunque atractivas per se, resultan arduas en su consecución. Inteligencia y voluntad, 
las dos potencias de la razón humana, se han visto comprometidas por el pecado original, por ende, resulta más difícil apreciar el bien y alcanzarlo. A esto se añade la rebeldía de la naturaleza respecto del hombre luego de su desobediencia al Creador. Esta rebelión de la naturaleza que presenta una dimensión personal, no podía permanecer ajena a la dimensión social del hombre, pues el hombre es persona siempre en relación, jamás en forma encapsulada. Wyszynski reconoce esta situación a través de estas conmovedoras palabras:

La sublevación contra la hermandad que el trabajo lleva consigo agrava, por su parte, ese sufrimiento. El colaborar con los hombres constituye una amargura desde el momento en que el pecado encerró al hombre en sí mismo, hundiéndole en el egoísmo y la soberbia, desde que violó el carácter social del hombre separándole de Dios y del prójimo, abocándole a la autoadoración, al culto de la propia inteligencia y voluntad (Wyszynski, 1958: 127128).

Siendo el trabajo una obra común, requiere de una dosis de sacrificio de la propia voluntad, de obediencia a la autoridad, de reconocimiento de los propios errores y de los aciertos y méritos de los demás. Pero aun en medio de las dificultades, de las fatigas, de las frustraciones, el hombre debe ser capaz de ver en el trabajo un camino de liberación, y esta liberación le viene dada al trabajo desde la redención.

\section{Trabajo y redención}

Para el tratamiento de esta cuestión, Wyszynski comienza con estas elocuentes palabras:

El trabajo hecho por amor a Dios es la participación humana, no sólo en la obra de la creación, sino también en la de la redención; toda labor, en efecto comporta una parte de fatiga y de agobio que podemos ofrecer al señor como expiación por las culpas humanas. Ese lado penoso del trabajo procede del enturbiamiento, por el pecado original, de la inteligencia y de la voluntad, que se oponen a las leyes benditas del trabajo (Wyszynski, 1958: 95).

Aparece aquí la triple relación del trabajo: con la creación, a la que el hombre se une mediante su actividad laboral practicada con amor al Creador; con el pecado, vinculación puesta de manifiesto en el "enturbiamiento" del que habla el Cardenal; y con la redención, en la 
incorporación del concepto de expiación de las culpas humanas, lo que se conoce como valor expiatorio del trabajo. Estas nociones también están contenidas en la encíclica de Juan Pablo II:

El sudor y la fatiga, que el trabajo necesariamente lleva en la condición actual de la humanidad, ofrecen al cristiano y a cada hombre que ha sido llamado a seguir a Cristo, la posibilidad de participar en el amor a la obra que Cristo ha venido a realizar. Esta obra de salvación se ha realizado a través del sufrimiento y de la muerte de cruz. Soportando la fatiga del trabajo en unión con Cristo crucificado por nosotros, el hombre colabora en cierto modo con el Hijo de Dios en la redención de la humanidad (Juan Pablo II, 1981: $\mathrm{n}^{\circ}$ 27).

¿Por qué dice "que el trabajo necesariamente lleva en la condición actual de la humanidad"? Porque, como vimos, el trabajo es anterior a la caída de Adán y Eva, el mandato de dominar la tierra precede al pecado original y, en esas condiciones, el sudor y la fatiga no le eran inherentes. A pesar de las dificultades que conlleva el ejercicio de cualquier labor, tan bien expresadas por el texto transcripto, se abre una ventana que nos introduce en la dimensión trascendente al vincular las penurias con la obra redentora de Cristo.

El esfuerzo adquiere entonces un aspecto purificador de nuestra inteligencia, de nuestra voluntad, de nuestros sentimientos, esfuerzo con el cual sintonizamos con el sacrificio redentor de Cristo en la cruz, para lo cual también requiere ser ejercido con amor. Por eso dice:

El trabajo sin amor, en efecto, es incapaz de redimir al hombre de sus culpas. "Cuando comáis, bebáis, o cualquier trabajo que hagáis, hacedlo todo para mayor gloria de Dios" (1 Cor 13, 3). La intención puede santificar la obra más insignificante, ser fuente de mérito redentor, si la dirige el amor a Dios (Wyszynski, 1958: 96).

La atinada introducción de estas palabras de san Pablo muestra la importancia que el trabajo adquiere en la gloria de Dios, no porque Dios necesite de ella, sino porque los hombres necesitamos glorificar a Dios con obras, para nuestra propia elevación personal, y el trabajo es una de las formas idóneas para hacerlo.

¿De qué manera se convierte el trabajo en fuente de redención? Veamos qué dice Wyszynski: 
En la resistencia que el trabajo encierra reconocemos la resistencia humana a Dios: la fatiga mediante la cual el hombre actúa sobre la materia, dignificándola, es similar al esfuerzo de Dios que actúa en el hombre para ennoblecerlo. Dios va mejorando constantemente en nosotros su obra para que refleje mejor su plan divino, la luz de su rostro. De manera análoga, el hombre, a su vez, comunica sus propios rasgos al objeto de su labor. Por la obra conocemos al maestro; sí, pero, en esta actividad humana sobre la materia, tropezamos con la resistencia de esta última, similar a la que el hombre opone a Dios. La materia acaba por ceder a la inteligencia y voluntad humanas y su sometimiento ha de servir al hombre de aliciente para que también él ceda a Dios (Wyszynski, 1958: 132).

Aunque algo extenso, vale la pena analizar este texto. El hilo conductor de su pensamiento es el paralelismo entre la resistencia de la materia al hombre y la resistencia del hombre a Dios. El esfuerzo que el hombre aplica a la materia para dignificarla, refleja el constante esfuerzo que Dios realiza para elevar al hombre. Obsérvese la nitidez con que el Cardenal expresa que el trabajo humano dignifica a la materia y no a la esencia humana. Se destaca también que, así como Dios va perfeccionando en nosotros su obra, el hombre expresa lo mejor de sí en su labor a través de los bienes que salen de sus manos. Finalmente, el tema de la resistencia, tanto de la naturaleza hacia el hombre, representada en este caso por la materia que debe someter, como la del hombre hacia Dios, al que opone su indocilidad. Con palabras llenas de un mensaje esperanzador, propio de quien confía tanto en la bondad y la misericordia de Dios, como en las mejores fuerzas humanas que son testimonio del espíritu con el que Dios dotó al hombre, el Cardenal expresa que así como la materia finalmente se le somete, también el hombre debe aceptar ceder a las insinuaciones de Dios, que desea para él la mayor de las perfecciones asequibles a su naturaleza racional.

\section{A modo de conclusión}

No es posible abarcar en el marco de un ensayo la maravillosa riqueza de todo un texto, y menos de uno como este sobre el que me propuse reflexionar específicamente respecto de la espiritualidad del trabajo. Pero de todos modos creo haber logrado suscitar, al menos, el interés por un libro que, algo olvidado, fue precursor de una encíclica de la magnitud y trascendencia de Laborem Exercens. 
A modo de conclusión deseo dejar un motivo de reflexión, para lo cual he escogido estas palabras de Wyszynski, elocuentes por sí mismas:

Y ahora, deduzcamos si el dolor del trabajo es una maldición, un castigo, o, por el contrario, una tabla de salvación más, una ocasión para que en nosotros se multiplique la gracia redentora. Veamos si hemos de desear y buscar trabajos cómodos, leves, exentos de esfuerzo; lo que tienda a ahorrar el esfuerzo humano, ¿no significará un empobrecimiento del hombre integral? La redención plena nos llegará de Cristo: "Venid a Mí todos los que trabajáis y estáis cargados, y Yo os aliviaré" (Wyszynski, 1958: 139).

\section{Referencias Bibliográficas}

Francisco (2013). Evangelii Gaudium.

Juan Pablo II (1981). Laborem Exercens. Buenos Aires: Ediciones Paulinas. Ratzinger, J. (2005). La Iglesia, una comunidad siempre en camino. Buenos Aires: San Pablo.

Villain, J. (1957). La enseña social de la Iglesia. Madrid: Aguilar. Wyszynski, S. (1958). El espíritu del trabajo. Madrid: Rialp.

${ }^{1}$ Rodríguez-Penelas, H. (2007). Aportes del cardenal Wyszynski en la gestación de Laborem Exercens. El tema de la espiritualidad del trabajo. Documento de Trabajo $\mathrm{N}^{\circ} 18$. Departamento de Economía de la Facultad de Ciencias Sociales y Económicas de la Universidad Católica Argentina. 